\title{
Capital Accumulation and Fiscal Policy in an OLG model with Family Altruism*
}

\author{
Stéphane LAMBRECHT \\ CORE (Université Catholique de Louvain) and GREMARS (Université Lille III) \\ and \\ Philippe MICHEL ${ }^{\dagger}$ \\ EUREqua (Université Paris I) and Université de la Méditerranée (GREQAM) \\ and \\ Emmanuel THIBAULT ${ }^{\S}$ \\ GREMAQ (Université Toulouse I) and Université de Perpignan (GEREM)
}

\begin{abstract}
The idea of family altruism is that parents care only about their children's income and not about the use of this income made by the children. First, we establish dynamical properties which place the OLG model with family altruism halfway between the model with pure life-cyclers (Diamond (1965)) and the one with dynastic altruism (Barro (1974)). Then, we show that this concept leads to interesting fiscal policy conclusions less clear-cut and more realistic than those obtained with the two previous standard OLG models: a pay as you go social security is neutral but not a public debt.
\end{abstract}

Keywords: Altruism, Fiscal Policy, Equilibrium.

JEL Classification: C 62 - D 64 - D 91.

\footnotetext{
*We thank Sabrina Buti, Olivier Charlot, Pierre Pestieau, Alain Venditti and Jean-Pierre Vidal for their comments and suggestions. We thank participants at the Macroeconomic Toulouse Seminar and CEPR Workshop on Financing retirement in Europe (Napoli, 9-10 may 2003) for their discussions.

${ }^{\S}$ GREMAQ - Manufacture des Tabacs - 21, allée de Brienne - 31000 Toulouse - France.

Tel: (+33)-5-61-12-85-57 Fax: (+33)-5-61-22-55-63 E-mail: emmanuel.thibault@univ-tlse1.fr
} 


\section{Introduction}

The OLG model is a standard tool for modelling dynamic economic behavior over discrete infinite time. Models of this profuse literature can be divided in two streams depending on whether households are life-cyclers or altruists, leaving positive bequests. For the macroeconomic analysis of fiscal policy, these two dominant models leads to opposite conclusions.

In OLG models with capital accumulation and life-cyclers, such as the one initially developed by Diamond (1965), the balanced growth path may be dynamically inefficient. Then there is a case for fiscal policy such as public debt or pay-as-you-go social security.

In dynastic OLG models with altruistic preferences (see Barro (1974)), the balanced growth path is efficient and there is no case for fiscal policy. Indeed, altruists exactly offset the positive or negative shocks on their income and on those of their dynasty. Barro's model turns out to be a model with infinitely-lived decision units, namely, the dynasties, whose members are linked through operative parental altruism. Then, the dynasty is the effective decision maker, since it is as long-lived as the government. Any individual belonging to any particular dynasty can observe the government's budget constraint and undo any redistribution, be it financed by current taxes (pay-as-you-go policies) or by future taxes (public debt policies).

Everything works as if on the one hand any model, which considers finite horizon as a reasonable feature of decision-making, should not consider altruistic transfers and, on the other hand, any model with altruistic transfers would end up with an infinite time horizon and yield neutrality of any public transfer policy.

In this paper, in order to solve this dilemma, we implement the concept of family altruism which is aimed at bridging the gap between Barro (1974) and Diamond (1965) models.

In most of the literature,${ }^{1}$ models of dynastic altruism consider that altruism links all the descendants of an individual into a single infinitely-lived entity. Models of pure life-cyclers feature another extreme view on private intergenerational linkages, according to which parents and children are fully distinct economic units. In figure 1 , we represent these links in the two polar canonical cases:

\footnotetext{
${ }^{1}$ See the survey of Michel, Thibault and Vidal (2005).
} 

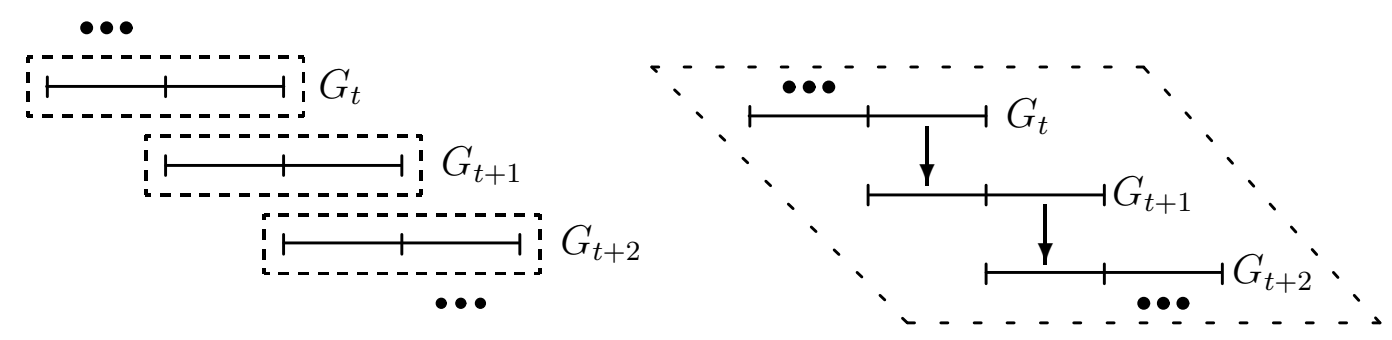

Figure 1: Diamond Case (left side) vs Barro Case (right side)

For all date $t$, each generation $G_{t}$ live two periods and, eventually, the straight arrows represent intergenerational private transfers and dashed boxes symbolize the relevant decision unit.

Recently, Mankiw (2000) gives facts which persuade economists that neither the Diamond model nor the Barro model is adequate for analyzing fiscal policy. These models are inconsistent with the empirical findings that consumption tracks current income and with the numerous households near zero wealth. In addition, the Diamond model is inconsistent with the great importance of bequests in aggregate wealth accumulation (see also Arrondel, Masson and Pestieau (1997)). Moreover in the Barro model there exists a complete harmony among all generations. As Becker and Tomes (1986) put it, this is at odd with the observation of strategic behavior between parents and children. Following Becker (1991), one can imagine a less drastic approach to modelling economic relations between parents and children.

The model of family altruism considers that a family is neither a dynasty nor an isolated household. Each individual starts a new family when he becomes adult. In turn, the individual's children start a new family, when adult themselves, and so on. In this setting, a family unit has a two-period lifetime. Each period there appear as many families as the number of young individuals and there disappear as many families as the number of dying old individuals. Individuals are members of two family units: the family founded by their parents and their own household. They play a different role in these two families. They belong the the former during their childhood and their adulthood and to the latter when adult and old. In the former, they make no decision, being completely passive when young and being only a descendant when adult. But in the latter they are full-fledged decision makers.

Family altruism are the sentiments between the two successive households. This is implemented by assuming that any individual values three objects: his first-period 
consumption, his second-period consumption and his offspring's adult disposable income. A standard approach of taking into account children is the joy of giving formulation in which only the gift matters (see Abel and Warshawsky (1988) or Andreoni (1989)). In this formulation the amount and structure of bequests are not related to children's relative affluence but rather to parental views on what is good for their children, or to the pleasure they derive from giving. So, our specification of preferences seems more adequate to implement family altruism and leads to interesting new properties. The altruist determines the starting position of his grown-up children: indeed, by making a transfer to his offspring, he helps them to get off to a good start. As a corollary, this specification ${ }^{2}$ also captures the idea that parents care about their children's income and not about the use of this income by their children. In particular, parents let their children use the bequest as they like in their respective families and they let them cope with taxes and transfers resulting from policies conducted after they die. Figure 2 represents the family structure of the family altruism concept.

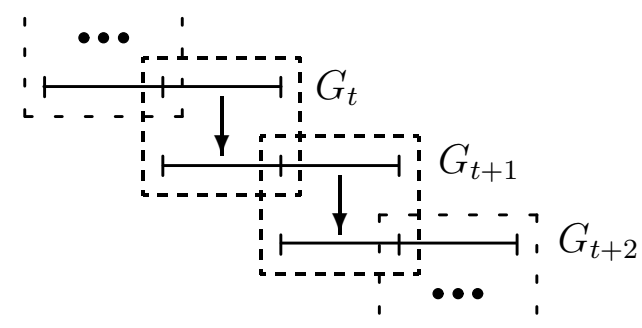

Figure 2: The Family Altruism Case

In such a setting, the altruist's action irons out the inequalities between the children's opportunities. Grand children are likely to benefit from this action but inequalities between them will be smoothed by their own parents.

Figure 1 and 2 tell us the following. In the Diamond model, life cycles are strictly unrelated to one another. In the Barro model, life cycles are embedded inside one another. In the family altruism model, they are hitched to one another.

The aims of this paper are to analyze the dynamical properties and to focus

\footnotetext{
${ }^{2}$ Some growth models with human capital use a similar concept of altruism. For example, the preference of an altruist in Glomm and Ravikumar (1992) depends on the quality of schools of his children. This variable is directly linked to the adult disposable income of his children. This problem with family altruism has been studied in Lambrecht, Michel and Vidal (2005).
} 
on fiscal policy conclusions of the OLG model with family altruism. Such a study allows us to differentiate our model from the two dominant OLG models developed by Diamond (1965) and Barro (1965) or from a mix of these standard models (Michel and Pestieau (1998, 1999) or Mankiw (2000)).

We first characterize the intertemporal equilibrium of our model using the key concept of "desired wealth", i.e. the wealth parents want for their children, which can be different from their effective wealth if altruism is not operative. We show how this feature, which is specific to family altruism, is articulated to savings and capital accumulation.

We also study in detail the dynamics of capital accumulation of the model with family altruism. Surprisingly enough, its monotonicity rests on fewer assumptions when altruism is operative than when it is not. The limits of the dynamics are also studied. Contrary to the Diamond model, an infinite limit of the capital intensity is possible. In the same way, a poverty trap in the economy without altruism can vanish with altruistic individuals.

Then, we examine the steady states of our model. In particular, we focus on the existence and multiplicity of equilibria with operative bequest motive. Interestingly, contrary to the Barro model, there may exist more than one steady state with positive bequests and there may exist a steady state with positive bequests which is inefficient.

The assessment of redistributive policies like public pensions or public debt goes through the examination of their impact on the total income of the family unit. Public pensions impact only inside the family. Taxpayers and pensions beneficiaries belong to the same decision unit. Thus, we show that, as in the Barro model, neutrality holds because family income remains unchanged. On the opposite, public debt extends beyond the family unit and thus modifies the pool of incomes of family members. Hence, as in Diamond model, public debt is not neutral.

As O'Driscol (1977) or Asso and Barucci (1988) remind us, Ricardo himself was convinced that, theoretically, there were no difference between taxes and public debt but that, in practice, people never think about the duration of taxes. Contrary to models with dynastic altruism, our model with family altruism supports these views. $^{3}$

\footnotetext{
${ }^{3}$ Ricardo (1820) underlined the limitation of the altruists' capacity to see throughout the whole
} 
To summarize our findings, the model with family altruism yields some new and surprising conclusions about fiscal policy and capital accumulation which places it halfway between the model with pure life-cyclers (Diamond (1965)) and the one with dynastic altruists (Barro (1974)).

The remainder of the paper is organized as follows. In section 2 we set up the model. In section 3 we establish results about the existence of an intertemporal equilibrium. The dynamics of capital are studied in Section 4 . In section 5 we focus on the existence and the properties of steady states. In section 6 we show that the concept of family altruism leads to interesting fiscal policy conclusions. Section 7 concludes.

\section{The model with family altruism}

We consider an OLG model in which agents live two periods. In period $t, N_{t}$ agents are young and supply one unit of labor. $N_{t}$ grows at rate $n$. The income $\omega_{t}$ of each of the $N_{t}$ young agents includes a bequests $x_{t}$ in addition to his wage income $w_{t}$. He consumes $c_{t}$ and saves $s_{t}$ :

$$
c_{t}+s_{t}=w_{t}+x_{t}=\omega_{t}
$$

In period $t+1$, when he is old, his income is the return on his savings: $R_{t+1} s_{t}$, where $R_{t+1}$ is the gross rate of return. He allocates this income to consume $d_{t+1}$ and to give a non-negative bequest $x_{t+1}$ to his $1+n$ children.

$$
R_{t+1} s_{t}=d_{t+1}+(1+n) x_{t+1} \quad \text { with } \quad x_{t+1} \geq 0
$$

His preferences depend on three quantities: consumption when young, $c_{t}$, consumption when old, $d_{t+1}$, and the income of his children (including bequest), $\omega_{t+1}$ :

$$
w_{t+1}+x_{t+1}=\omega_{t+1}
$$

future: "It would be difficult to convince a man posseded of 20,000 pounds, or any other sum, that a perpetual payment of 50 pounds per annum was equally burdensome with a single tax of 1000 pounds. He would have some vague notion that the 50 pounds per annum would be paid by posterity, and would not be paid by him; but if he leaves his fortune to his son, and leaves it charged with this perpetual tax, where is the difference whether he leaves him 20,000 pounds with the tax, or 19,000 pounds without it? This argument of charging posterity with the interest of our debt, or of relieving them from a portion of such interest, is often used by otherwise well informed people, but we confess we see no weight in it." 
We assume that these preferences are represented by a utility function which is additively separable:

$$
U\left(c_{t}, d_{t+1}, \omega_{t+1}\right)=u_{1}\left(c_{t}\right)+u_{2}\left(d_{t+1}\right)+\gamma u_{3}\left(\omega_{t+1}\right)
$$

Expliciting the parameter $\gamma>0$ allows to discuss, for a given function $u_{3}$, the effects of a change in the degree of altruism and to obtain the standard Diamond (1965) model for $\gamma=0$. The three functions $u_{i}, i=1,2,3$, are twice continuously differentiable on the set $\mathbb{R}_{+}^{\star}$ of real positive number and verify for all positive $e$ : $u_{i}^{\prime}(e)>0, u_{i}^{\prime \prime}(e)<0$. We also assume $\lim _{e \rightarrow 0} u_{i}^{\prime}(e)=+\infty$ and $\lim _{e \rightarrow+\infty} u_{i}^{\prime}(e)=0$.

The standard arbitrage condition over the life cycle is:

$$
u_{1}^{\prime}\left(c_{t}\right)=R_{t+1} u_{2}^{\prime}\left(d_{t+1}\right)
$$

The optimal choice of $x_{t+1}$ under the constraint $x_{t+1} \geq 0$ can be equivalently formulated in terms of the children wealth $\omega_{t+1} w_{t+1}+x_{t+1}$ and leads to

$$
\omega_{t+1}=\max \left\{w_{t+1}, \tilde{\omega}_{t+1}\right\}
$$

where $\tilde{\omega}_{t+1}$ is the unique positive solution of

$$
(1+n) u_{2}^{\prime}\left(R_{t+1} s_{t}+(1+n) w_{t+1}-(1+n) \tilde{\omega}_{t+1}\right)=\gamma u_{3}^{\prime}\left(\tilde{\omega}_{t+1}\right)
$$

Equation (7) is the arbitrage condition between the second period consumption of the old and the desired wealth of the children when ignoring the restriction $x_{t+1} \geq 0$. To study the dynamical properties of the OLG model with family altruism, the concept of "desired wealth" $\tilde{\omega}_{t+1}$ is very useful for dynamic analysis.

In period 0 , there are $N_{-1}$ agents who are old. Each of these agents holds a fraction $s_{-1}=K_{0} / N_{-1}$ of the initial capital stock $K_{0}$ and receives the return $R_{0} s_{-1}$. He allocates this income to consume $d_{0}$ and leave a bequest $x_{0}$ to each of his $1+n$ children. He maximizes $u_{2}\left(d_{0}\right)+\gamma u_{3}\left(\omega_{0}\right)$ subject to $R_{0} s_{-1}=d_{0}+(1+n) x_{0}, x_{0} \geq 0$, and $\omega_{0}=w_{0}+x_{0}$. The preceding analysis also applies to these choices. Thus the behavior of the first $N_{-1}$ old is characterized by the conditions (6) and (7) for $t=-1$.

The production side of the economy is standard. There is a representative firm which maximizes profits. The production function $\tilde{F}(K, L)$ is homogeneous of degree one with respect to capital $K$ and labor $L$. With a constant depreciation rate $\delta$ of 
capital, the sum of the production and the capital stock after depreciation $F(K, L)=$ $\tilde{F}(K, L)+(1-\delta) K$ is homogenous of degree one. Then we have $F(K, L)=L f(K / L)$, with $f(k)=F(k, 1)$ where $k=K / L$ is the capital intensity. The function $\mathrm{f}$ is continuous on $\mathbb{R}_{+}$and twice continuously differentiable on $\mathbb{R}_{+}^{\star}$. We assume that for all positive $k$ : $f(k)>0, f^{\prime}(k)>0$ and $f^{\prime \prime}(k)<0$.

For given prices, wage $w_{t}$ and gross return $R_{t}$, the maximum of profits: $F\left(K_{t}, L_{t}\right)-$ $w_{t} L_{t}-R_{t} K_{t}$ is obtained (with positive production) if (and only if) the marginal products are equal to the prices, i.e.:

$$
w_{t}=F_{L}^{\prime}\left(K_{t}, L_{t}\right)=f\left(k_{t}\right)-k_{t} f^{\prime}\left(k_{t}\right) \equiv w\left(k_{t}\right) \quad \text { and } \quad R_{t}=F_{K}^{\prime}\left(K_{t}, L_{t}\right)=f^{\prime}\left(k_{t}\right)
$$

From these relations we can define an intertemporal equilibrium the model with family altruism.

\section{The intertemporal equilibrium}

Given the initial capital stock $K_{0}$, an intertemporal equilibrium with perfect foresight is a sequence of prices $\left\{w_{t}, R_{t}\right\}_{t=0}^{+\infty}$, quantities for individual variables $\left\{c_{t}, s_{t}, d_{t}\right.$, $\left.x_{t}\right\}_{t=0}^{+\infty}$, and aggregate variables $\left\{L_{t}, K_{t}, Y_{t}, k_{t}\right\}_{t=0}^{+\infty}$ such that all agents behave optimally and all markets clear.

The stock $K_{0}$ is given and equal to $N_{-1} s_{-1}$ by definition of $s_{-1}$. At each period $t \geq 1$, the capital stock results from the savings of the preceding period $K_{t}=$ $N_{t-1} s_{t-1}$. The labor supply is $N_{t}$ and the labor market equilibrium implies $L_{t}=N_{t}$. The capital intensity is $k_{t}=K_{t} / N_{t}$, and the prices verify (8). Total production is $Y_{t}=N_{t} f\left(k_{t}\right)$ and the good market equilibrium results from the individual budget constraints and the firm's allocation of incomes: $Y_{t}=w_{t} N_{t}+R_{t} K_{t}$.

We shall show that at equilibrium all individual variables can be written as functions of the capital intensity. Let us first show this property for $\tilde{\omega}_{t+1}$, the solution of equation (7). According to (8), since $s_{t}=(1+n) k_{t+1}$ we have:

$$
R_{t+1} s_{t}+(1+n) w_{t+1}=(1+n)\left(k_{t+1} f^{\prime}\left(k_{t+1}\right)+w\left(k_{t+1}\right)\right)=(1+n) f\left(k_{t+1}\right)
$$

Hence, $\tilde{\omega}_{t+1}$ which is the solution of $(1+n) u_{2}^{\prime}\left((1+n) f\left(k_{t+1}\right)-(1+n) \tilde{\omega}_{t+1}\right)=\gamma u_{3}^{\prime}\left(\tilde{\omega}_{t+1}\right)$ is a function of $k_{t+1}$ and can be equivalently defined by:

$$
f\left(k_{t+1}\right)-\tilde{\omega}_{t+1}=\frac{1}{1+n} u_{2}^{\prime-1}\left(\frac{\gamma u_{3}^{\prime}\left(\tilde{\omega}_{t+1}\right)}{1+n}\right) \equiv \psi\left(\tilde{\omega}_{t+1}\right)
$$


From the assumption on $u, u_{i}^{\prime}$ are one-to-one decreasing functions from $\mathbb{R}_{+}^{\star}$ onto $\mathbb{R}_{+}^{\star}$. This implies that $\psi(\tilde{\omega})$ and $\tilde{\omega}+\psi(\tilde{\omega})$ are one to one increasing functions from $\mathbb{R}_{+}^{\star}$ onto $\mathbb{R}_{+}^{\star}$; and they are continuously differentiable. Thus equation (9) defines $\tilde{\omega}_{t+1}$ as a function $\tilde{\omega}$ of $k_{t+1}$ :

$$
\tilde{\omega}_{t+1}=\tilde{\omega}\left(k_{t+1}\right)
$$

The function $\tilde{\omega}$ is increasing and differentiable on $\mathbb{R}_{+}^{\star}$, and it verifies:

$$
0<\tilde{\omega}(k)<f(k) \quad \text { and } \quad \tilde{\omega}^{\prime}(k)=\frac{f^{\prime}(k)}{1+\psi^{\prime}(\tilde{\omega}(k))}>0
$$

At each period $t$, knowing $\tilde{\omega}_{t}=\tilde{\omega}\left(k_{t}\right)$, we obtain from $(6)$ :

$$
\omega_{t}=\omega\left(k_{t}\right)=\max \left\{w\left(k_{t}\right), \tilde{\omega}\left(k_{t}\right)\right\}
$$

We can now calculate $x_{t}=\omega\left(k_{t}\right)-w\left(k_{t}\right), c_{t}=\omega_{t}-s_{t}=\omega_{t}-(1+n) k_{t+1}$, and $d_{t}=f^{\prime}\left(k_{t}\right)(1+n) k_{t}-(1+n) x_{t}$.

The dynamics of the capital intensity, $(1+n) k_{t+1}=s_{t}$, is given at equilibrium by the savings decisions which result from condition (5). By substitution, we obtain:

$$
u_{1}^{\prime}\left(\omega_{t}-(1+n) k_{t+1}\right)=f^{\prime}\left(k_{t+1}\right) u_{2}^{\prime}\left((1+n)\left(f\left(k_{t+1}\right)-\omega_{t+1}\right)\right)
$$

or equivalently:

$$
\omega_{t}=(1+n) k_{t+1}+u_{1}^{-1}\left[f^{\prime}\left(k_{t+1}\right) u_{2}^{\prime}\left((1+n)\left(f\left(k_{t+1}\right)-\omega_{t+1}\right)\right)\right]
$$

Since the right hand side of $(13)$ is decreasing with respect to $\omega_{t+1}=\max \left\{w\left(k_{t+1}\right)\right.$, $\left.\tilde{\omega}\left(k_{t+1}\right)\right\}$, it can also be written as follows: ${ }^{4}$

$$
\omega\left(k_{t}\right)=(1+n) k_{t+1}+\min \left\{g_{0}\left(k_{t+1}\right), g_{1}\left(k_{t+1}\right)\right\}
$$

where functions $g_{0}$ and $g_{1}$ are:

$$
\begin{aligned}
& g_{0}(k)=u_{1}^{\prime-1}\left[f^{\prime}(k) u_{2}^{\prime}((1+n)(f(k)-w(k))]\right. \\
& g_{1}(k)=u_{1}^{\prime-1}\left[f^{\prime}(k) u_{2}^{\prime}((1+n)(f(k)-\tilde{\omega}(k))]\right.
\end{aligned}
$$

We have shown that:

\footnotetext{
${ }^{4}$ We can equivalently use equation (13) with $\omega_{\tau}=\omega\left(k_{\tau}\right)=\max \left\{w\left(k_{\tau}\right), \tilde{\omega}\left(k_{\tau}\right)\right\}$ at $\tau=t$ and $\tau=t+1$. Equation (14) uses explicitly the functional forms $g_{0}$ and $g_{1}$ which apply respectively when bequest are zero or are positive.
} 


\section{Proposition 1 The Intertemporal equilibrium}

Given $k_{0}=K_{0} / N_{0}$, an intertemporal equilibrium with perfect foresight is uniquely determined by a sequence of capital intensity $\left\{k_{t}\right\}_{t=0}^{+\infty}$ which verifies for all $t \geq 0$ the dynamic equation (14).

The functional form $g_{0}$ with zero bequest at date $t+1$ corresponds to the dynamics in the Diamond (1965) model without altruism (i.e. $\gamma=0$ ). In reference to the Diamond model, the variables of the model without altruism are noted by the upper-script $D$. Thus, the equilibrium dynamics in the Diamond model is:

$$
w\left(k_{t}^{D}\right)=(1+n) k_{t+1}^{D}+g_{0}\left(k_{t+1}^{D}\right)
$$

\section{Dynamics of the capital intensity}

For the dynamics with perfect foresight in the Diamond model to be well-defined it is sufficient that for all positive $k_{t}^{D}$, equation (17) admits a unique solution $k_{t+1}^{D}$. Let us first study the limits of the left hand side of equation (17). The limit when $k$ goes to $+\infty$ of $(1+n) k+g_{0}(k)$ is $+\infty$, since $g_{0}(k)$ is positive. For the limit when $k$ goes to 0 , since the limit of $f(k)-w(k)=k f^{\prime}(k)$ is zero, ${ }^{5}$ the limit of $f^{\prime}(k) u_{2}^{\prime}\left((1+n)(f(k)-w(k))\right.$ is $+\infty$, and the limit of $g_{0}(k)$ is zero. Thus we have:

$$
\lim _{k \rightarrow 0}(1+n) k+g_{0}(k)=0 \text { and } \lim _{k \rightarrow+\infty}(1+n) k+g_{0}(k)=+\infty
$$

These limit properties imply that for any positive $k_{t}^{D}$, there exists at least one value of $k_{t+1}^{D}$ solution of (17). In order to obtain a unique value of $k_{t+1}^{D}$ solution of (17), one needs an additional assumption. The following condition is a sufficient condition for the dynamics in the Diamond model are well defined.

\section{Assumption 1 Determinacy of the dynamics in the Diamond model} The function $(1+n) k+g_{0}(k)$ is strictly increasing.

The relevance of this assumption has been underlined by de la Croix and Michel (2002). They exhibit conditions under which Assumption 1 is satisfied. For example, it is the case when the elasticity of $u_{2}^{\prime}$ is greater or equal to one.

\footnotetext{
${ }^{5}$ No assumption on $f$ at $k=0$ is necessary. We have with the mean value theorem for derivatives (with $0<\theta<1$ ): $f(k)-f(0)=k f^{\prime}(\theta k)>k f^{\prime}(k)>0$ and taking the limit when $k$ goes to 0 , we obtain $\lim _{k \rightarrow 0} k f^{\prime}(k)=0$. The limit of $f^{\prime}(k)$ is either finite and positive or $+\infty$. In both cases, $\lim _{k \rightarrow 0} f^{\prime}(k) u_{2}^{\prime}((1+n)(f(k)-w(k))=+\infty$.
} 
We now study the dynamics of the capital intensity in the model with family altruism. Since the dynamics in the Diamond model are well defined, we can compare the two dynamics.

\section{Proposition 2 Dynamics of CAPITAL Intensity}

(i) Under Assumption 1, for all positive $k_{0}$, there exists a unique intertemporal equilibrium with perfect foresight starting at $k_{0}$.

(ii) The dynamics of the capital intensity are monotonic.

(iii) For all $t$, the dynamics verify $k_{t} \geq k_{t}^{D}$ where $k_{t}^{D}$ is the solution of the dynamics in the economy without altruism starting at the same initial level $k_{0}$.

Proof: $(i)$ The existence for all $k_{t}$ of at least one solution $k_{t+1}$ of equation (14) results simply from the limit value of the right hand side. Indeed we have $0 \leq$ $\lim _{k \rightarrow 0} \min \left\{g_{0}(k), g_{1}(k)\right\} \leq \lim _{k \rightarrow 0} g_{0}(k)=0$ and $\lim _{k \rightarrow+\infty}(1+n) k+\min \left\{g_{0}(k), g_{1}(k)\right\}$ $=+\infty$ since $g_{0}(k)$ and $g_{1}(k)$ are non negative.

The function $g_{1}(k)$ is strictly increasing; indeed its derivative $g_{1}^{\prime}$ is equal to $\left[f^{\prime \prime} u_{2}^{\prime}+f^{\prime} u_{2}^{\prime \prime}(1+n)\left(f^{\prime}-\tilde{\omega}^{\prime}\right)\right] / u_{1}^{\prime \prime}$ and from (11), $f^{\prime}-\tilde{\omega}^{\prime}$ is positive.

With Assumption $1,(1+n) k+\min \left\{g_{0}(k), g_{1}(k)\right\}$ is a strictly increasing function of $k$. This implies the uniqueness of $k_{t+1}$ solution of (14) for given $k_{t}$.

(ii) Since $\omega\left(k_{t}\right)$ is also an increasing function of $k_{t}$, the dynamics are monotonic.

(iii) Let us show $k_{t} \geq k_{t}^{D}$ by induction. This is true at $t=0$ since $k_{0}^{D}=k_{0}$. Assume that it is verified at $t: k_{t} \geq k_{t}^{D}$. Then, according to (14) we have: $\omega\left(k_{t}\right) \geq$ $w\left(k_{t}\right) \geq w\left(k_{t}^{D}\right)=(1+n) k_{t+1}^{D}+g_{0}\left(k_{t+1}^{D}\right)$

But $\omega\left(k_{t}\right)=(1+n) k_{t+1}+g_{0}\left(k_{t+1}\right)$ and the function $(1+n) k+g_{0}(k)$ is increasing (Assumption 1). This implies $k_{t+1} \geq k_{t+1}^{D}$. QED

The intuition that the capital stock is larger in the economy with family altruism than in the model without altruism is simple. Any agent willing to leave a bequest has to save more; this of course increases the capital stock.

Since the equilibrium dynamics are monotonic, they converge either to $+\infty$, or to zero, or to a finite positive limit which is a steady state. We now focus on the two first cases while the study of steady states will be treated in section 5 .

In the Diamond model, an infinite limit of the capital intensity is excluded (see, for example, Jones et Manuelli (1992)). In addition it may exist a poverty trap, i.e., an equilibrium dynamics which converge to zero (see Galor and Ryder (1989)). 
The introduction of the assumption of altruism allows to increase the capital intensity. Therefore, unlike the model without altruism, the model with family altruism can converge to $+\infty$. In the same way, a poverty trap in the economy without altruism can vanish with altruistic individuals (for illustrating examples see Lambrecht, Michel and Thibault (2000)).

We can notice that our dynamic study has been conducted without restriction on whether the economy is in a regime with positive or zero bequest. In the next section, we refine this "general" study by exploring the long run regime of the economy.

\section{The long run regime}

In general, there are several steady states in the Diamond economy (see Galor and Ryder (1989)). Each of these states is potentially a steady state in an economy with altruism, when altruism is weak enough for the equilibrium bequest to be zero (see Thibault (2000) for dynastic altruism). We consider this point in the case of family altruism.

Steady states of the Diamond model are solutions of: $w(k)=(1+n) k+g_{0}(k)$. Such a value of $k^{D}$ is a steady state (with zero bequests) of the economy with family altruism if and only if $\tilde{\omega}\left(k^{D}\right) \leq w\left(k^{D}\right)$. By definition, $\tilde{\omega}\left(k^{D}\right)$ is the value of $\omega$ such that the increasing function

$$
(1+n) u_{2}^{\prime}\left[(1+n) f^{\prime}\left(k^{D}\right) k^{D}+(1+n) w\left(k^{D}\right)-(1+n) \omega\right]-\gamma u_{3}^{\prime}(\omega)
$$

is equal to zero. Thus the inequality $\tilde{\omega}\left(k^{D}\right) \leq w\left(k^{D}\right)$ is equivalent to

$$
(1+n) u_{2}^{\prime}\left[(1+n) f^{\prime}\left(k^{D}\right) k^{D}\right] \geq \gamma u_{3}^{\prime}\left(w\left(k^{D}\right)\right)
$$

This condition is simply an upper bound on the degree of altruism $\gamma$ (different for different steady states $k^{D}$ ). Using this condition, we prove in Appendix A the following proposition:

\section{Proposition 3 Existence of steady states}

The steady states with zero bequest in the economy with family altruism are the steady states of Diamond model which satisfy (19). If such a steady state $k^{D}$ does not satisfy (19), then there exists a steady state in the economy with family altruism which is larger than $k^{D}$. 
We now focus on the steady states of the economy with family altruism and positive bequests. According to the previous result, when the largest Diamond steady state does not satisfy (19), the model with family altruism has a steady state with positive bequests. In the Barro model, the modified Golden Rule is the unique equilibrium with positive bequests. With family altruism there may exist more than one steady state with positive bequests and there may exist a steady state with positive bequests which is inefficient (i.e. over-accumulation of capital). But such an inefficient steady state is excluded if the the Golden Rule capital stock $\hat{k}$, i.e., such that $f^{\prime}(\hat{k})=1+n$, satisfies the following condition:

$$
u_{1}^{\prime}[\hat{\omega}-(1+n) \hat{k}]>(1+n) u_{2}^{\prime}[(1+n)(f(\hat{k})-\hat{\omega})]
$$

where $\hat{\omega}$ is the solution of: $(1+n) u_{2}^{\prime}[(1+n)(f(\hat{k})-\hat{\omega})]=\gamma u_{3}^{\prime}(\hat{\omega})$.

Indeed we prove in Appendix B the following proposition:

\section{Proposition 4 Steady States with Positive Bequests}

A multiplicity of steady states with positive bequests can exist but no more than one with over-accumulation of capital. A sufficient condition for excluding overaccumulation of capital is that the golden rule capital stock $\hat{k}$ satisfies (21).

The property of no more than one steady state with positive bequest and overaccumulation needs no assumption. The condition which excludes inefficiency holds if the degree of altruism is not too large. Indeed, the solution $\hat{\omega}(\gamma)$ of $(1+n) u_{2}^{\prime}[(1+$ $n)(f(\hat{k})-\hat{\omega})]=\gamma u_{3}^{\prime}(\hat{\omega})$ is an increasing function of $\gamma$. It increases from 0 to $f(\hat{k})$ when $\gamma$ increases from 0 to $+\infty$. But the condition $(21)$ is equivalent to $\hat{\omega}<\bar{\omega}$, where $\bar{\omega}$ equalizes to zero the decreasing function of $\omega, u_{1}^{\prime}[\omega-(1+n) \hat{k}]-(1+$ $n) u_{2}^{\prime}[(1+n)(f(\hat{k})-\omega)]$, which decreases from $+\infty$ to $-\infty$ when $\omega$ increases from $(1+n) \hat{k}$ to $f(\hat{k})$. Then the condition $(21)$, equivalent to $\hat{\omega}(\gamma)<\bar{\omega}$, determines an upper-bound $\bar{\gamma}$ on $\gamma{ }^{6}$

Without additional assumptions, there can be many steady states with positive bequests. There is an analogy with the possibility of several steady states in the Diamond model. Galor and Ryder (1989) exhibit a production function which illustrates this case, in which multiplicity is linked to non-concavity of the wage function.

\footnotetext{
${ }^{6}$ In the particular case where for all $\omega$ we have $u_{3}^{\prime}(\omega) \leq u_{1}^{\prime}(\omega)$ there exists no steady state with positive bequest in over accumulation when $\gamma \leq 1$. Indeed, at a steady state with positive bequest we have: $u_{1}^{\prime}(c)=R u_{2}^{\prime}(d)=\frac{R}{1+n} u_{3}^{\prime}(\omega) \leq \frac{\gamma R}{1+n} u_{1}^{\prime}(\omega)$ and $c=\omega-s<\omega$ implies $f^{\prime}(k)=R>$ $(1+n) / \gamma \geq 1+n$ when $\gamma \leq 1$. Any steady state then verifies $k<\hat{k}=f^{\prime-1}(1+n)$.
} 
In the model with family altruism, when bequests are positive, the wealth $\tilde{\omega}(k)$ is simply linked to the production (equation (9)) and not to the wage. Irregularities then result from the utility functions and in the example of Appendix we show that there exists a concave utility function $u_{3}$ leading to as many steady states with positive bequests as we want. ${ }^{7}$

\section{$6 \quad$ Fiscal policies}

We now study fiscal policies under the assumption of operative altruism. In the general case, the government budget constraint combines public spending $\left(G_{t}\right)$ and previous debt reimbursement ${ }^{8}$ at time $t\left(R_{t} B_{t-1}\right)$, on the one hand, taxes collected on the young $\left(N_{t} \tau_{t}^{1}\right)$ and on the old $N_{t-1} \tau_{t}^{2}$ (positive or negative) and new debt issue on the other $\left(B_{t}\right)$ :

$$
G_{t}+R_{t} B_{t-1}=N_{t} \tau_{t}^{1}+N_{t-1} \tau_{t}^{2}+B_{t}
$$

Since individual preferences do not depend on public expenditures and since we focus on purely redistributive fiscal policies, we set $G_{t}=0$. The total amount of taxes $T_{t}$ is equal to the sum of the taxes bearing on young and old at time $t$ :

$$
T_{t}=N_{t} \tau_{t}^{1}+N_{t-1} \tau_{t}^{2}
$$

Thus the government budget constraint writes :

$$
R_{t} B_{t-1}=T_{t}+B_{t}
$$

A pay-as-you-go pension system is a special case of this government budget constraint with, for all $t, B_{t}=0$ and $N_{t} \tau_{t}^{1}=N_{t-1}\left(-\tau_{t}^{2}\right)$. Let $b_{t}=B_{t} / N_{t}$ and $t_{t}=T_{t} / N_{t}=\tau_{t}^{1}+(1+n)^{-1} \tau_{t}^{2}$, then time $t$ new bonds issue per head of young individuals are given by :

$$
b_{t}=(1+n)^{-1} R_{t} b_{t-1}-t_{t}
$$

Let us sketch quickly the amendments to the model without public debt. The introduction of governmental taxes modifies the individuals' constraints as follows:

$$
c_{t}+s_{t}=w_{t}+x_{t}-\tau_{t}^{1}=\omega_{t}
$$

\footnotetext{
${ }^{7}$ With a CES utility function, the steady state is unique (see Lambrecht, Michel and Thibault $(2000))$.

${ }^{8}$ Bonds are assumed to have a single period maturity.
} 


$$
\begin{gathered}
R_{t+1} s_{t}-\tau_{t+1}^{2}=d_{t+1}+(1+n) x_{t+1} \\
\omega_{t+1}=w_{t+1}+x_{t+1}-\tau_{t+1}^{1}
\end{gathered}
$$

The individuals' first-order conditions remain unchanged. The representative firm's behavior is unaffected.

Governmental bonds compete with private physical capital. If bonds are to be exchanged in equilibrium, they must bear the same return than physical capital. In equilibrium we now have :

$$
s_{t}=(1+n) k_{t+1}+b_{t}
$$

In the model without public debt, $\omega_{t+1}$ solves $(1+n) u_{2}^{\prime}\left(d_{t+1}\right)=u_{3}^{\prime}\left(\omega_{t+1}\right)$, with $d_{t+1}=R_{t+1}(1+n) k_{t+1}-(1+n)\left(\omega_{t+1}-w\left(k_{t+1}\right)\right)$ and is an increasing function of capital intensity $k_{t+1}$. In the model with public debt, it solves $(1+n) u_{2}^{\prime}\left(d_{t+1}\right)=$ $u_{3}^{\prime}\left(\omega_{t+1}\right)$ with $d_{t+1}=R_{t+1} s_{t}-\tau_{t+1}^{2}-(1+n) x_{t+1}$. Using the modified $x_{t+1}=\omega_{t+1}-$ $w\left(k_{t+1}\right)+\tau_{t+1}^{1}$ and $s_{t}=(1+n) k_{t+1}+b_{t}$, as well as the government budget constraint (22), this expression of $d_{t+1}$ can be rewritten as follows :

$$
d_{t+1}=(1+n)\left[f\left(k_{t+1}\right)+b_{t+1}-\omega_{t+1}\right]
$$

Consequently equation (9) becomes: $f\left(k_{t+1}\right)+b_{t+1}-\omega_{t+1}=\psi\left(\omega_{t+1}\right)$ and the young disposable income can be written as a function $\tilde{\omega}$ of $k_{t+1}$ and $b_{t+1}$ from:

$$
\omega_{t+1}+\psi\left(\omega_{t+1}\right)=f\left(k_{t+1}\right)+b_{t+1}
$$

The function $\tilde{\omega}$ has the following properties:

$$
\tilde{\omega}_{k}^{\prime}=\frac{f^{\prime}}{1+\psi^{\prime}}>0 \quad \text { and } \quad \tilde{\omega}_{b}^{\prime}=\frac{1}{1+\psi^{\prime}} \in(0,1)
$$

With respect to the model without policy, public debt modifies the allocation between the old's consumption $\psi\left(\omega_{t+1}\right)$ and the young's income $\omega_{t+1}$ because the size of the "cake" to be divided in each period is now $f\left(k_{t+1}\right)+b_{t+1}$

We now turn the the dynamics of capital intensity. The equation (13) describing the motion of capital intensity becomes

$$
\widetilde{\omega}\left(k_{t}, b_{t}\right)=(1+n) k_{t+1}+b_{t+1}+g_{1}\left(k_{t+1}, b_{t+1}\right) \equiv G\left(k_{t+1}, b_{t+1}\right)
$$

with: $g_{1}=u_{1}^{-1}\left[f^{\prime}\left(k_{t+1}\right) u_{2}^{\prime}\left((1+n)\left(f\left(k_{t+1}\right)+b_{t+1}-\tilde{\omega}\left(k_{t+1}, b_{t+1}\right)\right)\right)\right]$.

It is interesting to note that in the equilibrium dynamics (equation (24)), the level of public debts matters but not the taxes or the transfers. In the economy with 
family altruism, the two policies of public debt and intergenerational transfers are not equivalent, although they are equivalent in the Diamond economy (Buiter and Kletzer (1998)) and in the Barro economy (since both are neutral).

The property of non-equivalence can be explained by considering the family income of one period which is equal to the sum of the income of the old agent and the income of his $1+n$ children, i.e. in period $t+1$ :

$$
\Omega_{t+1}=R_{t+1} s_{t}+(1+n) w_{t+1}
$$

This income finances the consumption of the old $d_{t+1}$ and the income of the young $(1+n) \omega_{t+1}$. This income is modified by a change in debt policy, because $s_{t}=(1+n) k_{t+1}+b_{t}$ is modified. Then, the optimal arbitrage in period $t+1$ between $d_{t+1}$ and $\omega_{t+1}$, i.e. the solution of maximizing $u_{2}\left(d_{t+1}\right)+\gamma u_{3}\left(\omega_{t+1}\right)$ subject to $d_{t+1}+(1+n) \omega_{t+1}=\Omega_{t+1}$, is also modified.

It is also interesting to note that the same arbitrage applies when there is a second period additional income of the old. For example, if there is a supply of $\theta$ units of labor in the second period of life, the family income in period $t+1$ is:

$$
\Omega_{t+1}=R_{t+1} s_{t}+\theta w_{t+1}+(1+n) w_{t+1}
$$

The second period of life income of the young will occur in period $t+2$ and does not enter in the family income of period $t+1$. It will enter the young's own family income of period $t+2$ together with taxes and transfers of period $t+2$.

Note finally that if we want explicitly to introduce an additional income in the last period of life, this additional income must be correlated with the capital accumulation. In other words, we cannot work in an exchange economy framework. As a result, there are not many papers dealing with non ad-hoc ways of introducing an additional income in the last period of life linked to the capital stock. However according to Decreuse and Thibault $(2001)^{9}$, our next fiscal policy results are robust to the introduction of an additional income in the last period of life as in the Diamond's framework.

\footnotetext{
${ }^{9}$ Recently, by contrast to Diamond (1965), Decreuse and Thibault (2001) consider a very simple OLG model in which agents work during their second period of life. They assume that there is an age-specific labor productivity which is related to the age-earnings profile studied in labor economics. The authors exhibit sufficient conditions ruling out dynamic inefficiency (or, equivalently the non-neutrality of public debt) if age-specific labor productivity is sufficiently strong.
} 


\section{Proposition 5 Determination of the intertemporal EqUilibrium}

Given initial conditions $k_{0}$ and $b_{-1}=0$, the intertemporal equilibrium $\left\{k_{t+1}\right\}_{t=0}^{+\infty}$ with unconstrained bequests is determined by the sequence of public debt levels (per young, $\left.\left\{b_{t}\right\}_{t=1}^{+\infty}\right)$, or, equivalently, by the sequence of total taxes (per young, $\left.\left\{t_{t}\right\}_{t=0}^{+\infty}\right)$. As long as bequests are unconstrained, the intertemporal equilibrium does not depend on the allocation of taxes between the young and the old.

Proof: Equation (24) only involves capital intensities and debt levels. The equivalence between tax levels $t_{t}$ and debt levels $b_{t}$ in determining the equilibrium comes from the budget constraint $b_{t}=(1+n)^{-1} R_{t} b_{t-1}-t_{t}$. At each period $t$, given the debt level $b_{t-1}$, choosing $t_{t}$ implies the debt level $b_{t}$. Alternatively, choosing a debt level $b_{t}$ implies a tax level $t_{t}$. QED

From this proposition it is straightforward to deduce the following result:

\section{Proposition 6 NeUtrality of a PAY-AS-YOU-Go PENSION SYSTEM}

A special case of the preceding proposition is obtained with no debt, i.e. with pay-as-you-go pension system. In that case, proposition 5 means that there is no effect on the equilibrium

Proof: Pay-as-you-go policies are equivalent to $b_{t}=0$. Thus the dynamics are unchanged with respect to the absence of fiscal policy. QED

The interpretation of this result is that transfers inside the family completely offset public transfers. Any increase in the taxes levied on the young is compensated by an increase in the old's bequest. Indeed, as you can see in Figure 3, public intergenerational transfers (the broken arrows) generated by the pay-as-you-go pension system are neutralized inside the family unit by private intergenerational transfers (the straight arrows).

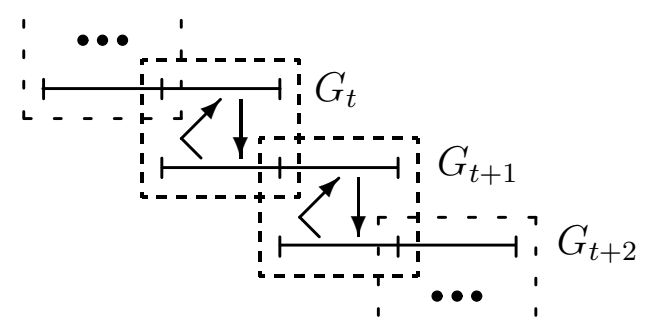

Figure 3: Neutrality of PAYG Social Security - The Family Altruism Case 
This feature is thus common to the family altruism model and the dynastic altruism model. Indeed, Figure 4 explains intuitively why a pay-as-you-go pension system is neutral in the Barro's framework but not in the Diamond's one.
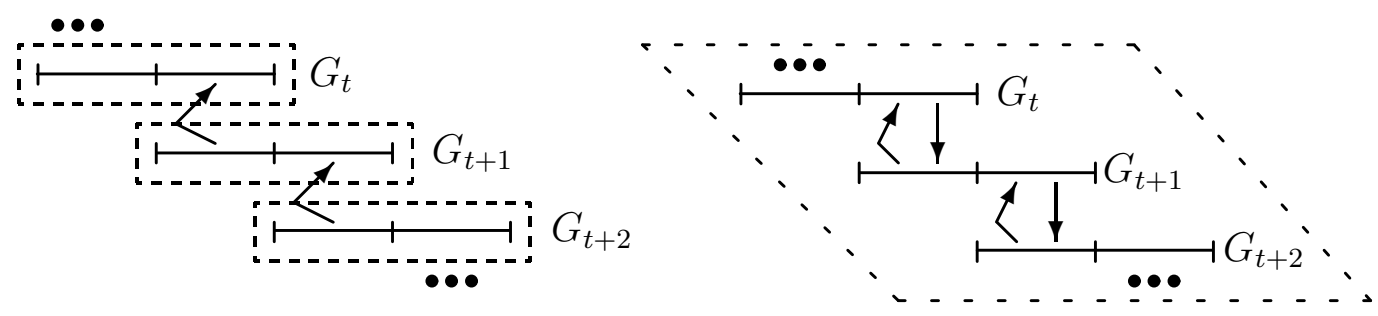

Figure 4: PAYG Social Security - Diamond (left side) vs Barro (right side)

Let us focus now on the effects of public debt in our model with family altruism:

\section{Proposition 7 The effects of Public DeBT}

An increase public debt $b_{t+1}$ in period $t+1$ increases consumption of the generation born in $t, c_{t}$ and $d_{t+1}$ and reduces the capital stock in all the following periods.

Proof: We first compute $d k_{t+1} / d b_{t+1}$. We have:

$$
\begin{aligned}
g_{1 k}^{\prime} & =\left[f^{\prime \prime} u_{2}^{\prime}+f^{\prime} u_{2}^{\prime \prime}(1+n)\left(f^{\prime}-\tilde{\omega}_{k}^{\prime}\right)\right] u_{1}^{\prime \prime-1}>0 \\
G_{k}^{\prime} & =(1+n)+g_{1 k}^{\prime}>0 \\
g_{1 b}^{\prime} & =f^{\prime} u_{2}^{\prime \prime} u_{1}^{\prime \prime-1}(1+n)\left(1-\tilde{\omega}_{b}^{\prime}\right)>0 \\
G_{b}^{\prime} & =1+g_{1 b}^{\prime}>0
\end{aligned}
$$

Hence, $d k_{t+1} / d b_{t+1}=-G_{b}^{\prime} / G_{k}^{\prime}<0$. The dynamics are monotonic : thus the capital stock is reduced in all the following periods. Then we compute $\partial c_{t} / \partial b_{t+1}$, the effect on consumption at time $t$, with $c_{t}=\tilde{\omega}\left(k_{t}, b_{t}\right)-(1+n) k_{t+1}$ and $\partial d_{t+1} / \partial b_{t+1}$, the effect on consumption at time $t+1$, with $d_{t+1}=(1+n)\left[f\left(k_{t+1}\right)+b_{t+1}-\tilde{\omega}\left(k_{t+1}, b_{t+1}\right)\right]$. Then:

$$
\frac{\partial c_{t}}{\partial b_{t+1}}=-(1+n) \frac{d k_{t+1}}{d b_{t+1}}>0
$$

Since $u_{1}^{\prime}\left(c_{t}\right)=f^{\prime}\left(k_{t+1}\right) u_{2}^{\prime}\left(d_{t+1}\right)$ we have:

$$
u_{1}^{\prime \prime} \frac{\partial c_{t}}{\partial b_{t+1}}=f^{\prime} u_{2}^{\prime \prime} \frac{\partial d_{t+1}}{\partial b_{t+1}}+f^{\prime \prime} u_{2}^{\prime} \frac{\partial k_{t+1}}{\partial b_{t+1}}
$$

Then: $f^{\prime} u_{2}^{\prime \prime} \frac{\partial d_{t+1}}{\partial b_{t+1}}=\frac{\partial k_{t+1}}{\partial b_{t+1}}\left(-(1+n) u_{1}^{\prime \prime}-f^{\prime \prime} u_{2}^{\prime}\right)<0$, and $\partial d_{t+1} / \partial b_{t+1}>0$. QED 
This is in line with the conventional view of public debt. This view distinguishes between short run effects and long run effects. In the short run, each household spends more on consumption goods. This leads to an increase in aggregate demand for output and to an increase in national income. However capital accumulation is reduced by substitution of government bonds to firm assets. Precisely, our proposition shows that the increase in debts at some date increases the consumption of the old generation at the current period and decreases the capital stock available for production.

Intuitively, public debt is not neutral in our setting because, according to Figure 5 , public intergenerational transfers (the broken arrows) generated by the public debt can not be neutralized inside the family unit by private intergenerational transfers (the straight arrows).

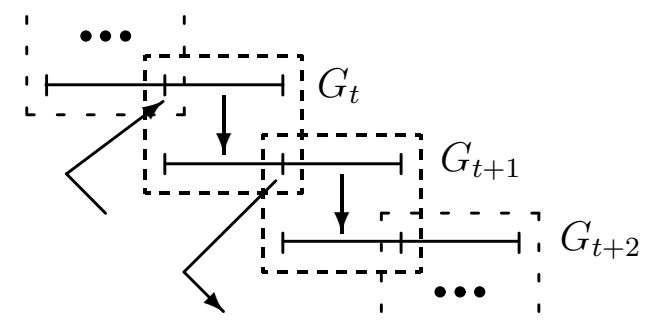

Figure 5: Non Neutrality of Public Debt - Family Altruism Case

The non-neutrality result of public debt in the family altruism model is a common feature with the Diamond model. Indeed, Figure 6 explains intuitively why a public debt policy is neutral in the Diamond's framework but not in the Barro's one.
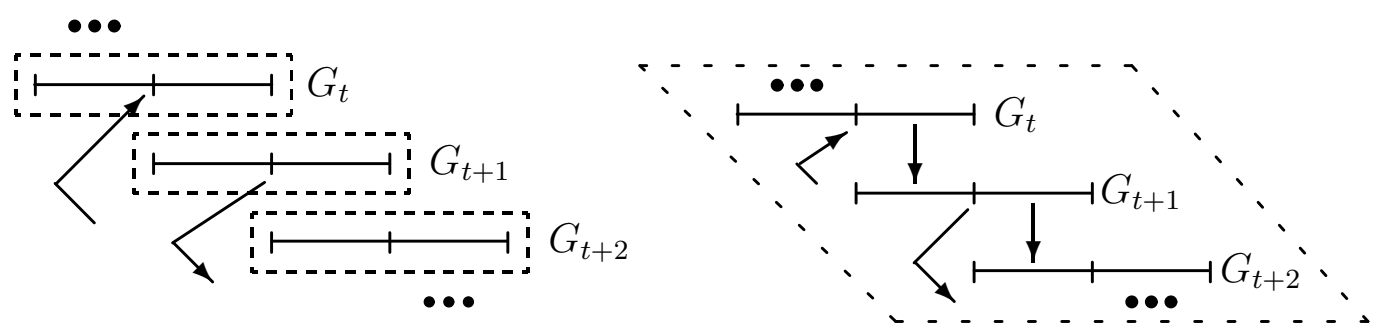

Figure 6: Public Debt - Diamond (left side) vs Barro Case (right side)

Then, family altruism is the first concept of altruism which leads to fiscal policy conclusions that are less clear-cut than those obtained in the canonical macrodynamic models with pure life-cyclers (Diamond (1965)) and the ones of the dynastic 
altruism (Barro (1974)) and the ones with warm glow altruism (Andreoni (1989)).Indeed, this concept allows to differentiate the effect of a public debt policy and of a pay as you go social security.

\section{Conclusion}

We studied an amended formulation of the altruistic transfer motive in the framework of an OLG model. The idea of the family altruism used in this paper is that altruistic parents care only about their children income and not about the use of this income made by the children. Models with human capital (see e.g. Glomm and Ravikumar (1992)) have used this particular specification of altruism of the adult disposable income. In this paper, we translate it to a model with physical capital.

\begin{tabular}{|c||c|c|c|c|}
\hline & $\begin{array}{c}\text { Altruism } \\
\text { à la Barro }\end{array}$ & $\begin{array}{c}\text { Family } \\
\text { altruism }\end{array}$ & $\begin{array}{c}\text { Diamond } \\
\text { model }\end{array}$ & $\begin{array}{c}\text { joy of giving } \\
\text { altruism }\end{array}$ \\
\hline \hline $\begin{array}{c}\text { Horizon of } \\
\text { foresight }\end{array}$ & Infinite & One period & One period & One period \\
\hline $\begin{array}{c}\text { Neutrality of a pay } \\
\text { as you go pension }\end{array}$ & Yes & Yes & No & No \\
\hline $\begin{array}{c}\text { Neutrality of } \\
\text { a public debt }\end{array}$ & Yes & No & No & No \\
\hline $\begin{array}{c}\text { Uniqueness of } \\
\text { the steady state }\end{array}$ & Yes & No & No & No \\
\hline $\begin{array}{c}\text { Possibility of existence } \\
\text { of equilibrium with } \\
\text { overaccumulation }\end{array}$ & No & Yes & Yes & Yes \\
\hline $\begin{array}{c}\text { Unlimited } \\
\text { growth }\end{array}$ & Yes & Yes & No & Yes \\
\hline
\end{tabular}

Table 1: Barro vs Family altruism vs Diamond vs Joy of giving

It is convenient to summarize our results by systematically comparing them with those of the Barro and the Diamond model. As it is shown in the table 1, the family altruism model has two common points with the Barro model: the neutrality of pay-as-you-go pensions and the possibility of unlimited growth. With respect to the Diamond model, it has four common points: the one-period horizon of foresight, the non-neutrality of public debt, the possibility of multiple steady states and, finally, the possibility of existence of an equilibrium in over-accumulation. We also compare 
these results with the conclusions of the joy of giving model. For this model, the only difference with the Diamond model in Table 1 is the possibility of unlimited growth.

In the light of our findings, the family formulation of altruism might act as filling in a gap between the life-cycle model and Barro's dynastic model of altruism which are the two benchmarks of the economic analysis of intertemporal choices and dynamics. Throughout our analysis, the concept of desired wealth revealed how central it was. At the level of decision-making, it suitably summarizes the altruist's possibly constrained bequest choice. At the level of the intertemporal equilibrium, it proved to be quite useful in establishing the monotonicity of the dynamics. Finally note that the introduction of the assumption of altruism allows to increase the capital intensity. Therefore, a poverty trap in the Diamond economy can vanish with individuals motivated by family altruism or by joy of giving. 


\section{References}

[1] Abel, A.B. and M. Warshawsky, 1988, Specification of the joy of giving: insights from altruism, The Review of Economics and Statistics, 70, 145-149.

[2] Andreoni, J., 1989, Giving with impure altruism: applications to charity and Ricardian equivalence, Journal of Political Economy, 96, 1447-1458.

[3] Asso, P. and E. Barucci, 1988, Ricardo on the national debt and its redemption: some notes on an unpublished ricardian manuscript, Economic Notes, 2, 5-36.

[4] Barro, R.J., 1974, Are government bonds net wealth?, Journal of Political Economy, 82, 1095-1117.

[5] Becker, G., 1991, A treatise on the family, Enlarged edition Cambridge, Mass. and London: Harvard University Press.

[6] Becker, G.S. and N. Tomes, 1986, Human capital and the rise and fall of families, Journal of Labor economics, 4, S1-S39.

[7] Buiter, W.H. and K.M. Kletzer, 1998, Debt and taxes: Ponzi finance, dynamic efficiency and government solvency, in Market behaviour and macroeconomic modelling, Brakman, Van Ees and Kuipers eds, London: Mc Millan Press.

[8] de la Croix, D. and Ph. Michel, 2002, A theory of economic growth: dynamics and policy in overlapping generations, Cambridge University Press.

[9] Decreuse, B. and Thibault, E., 2001, Labor Productivity and Dynamic Efficiency, Economics Bulletin, 4, 1-6.

[10] Diamond, P.A., 1965, National debt in a neoclassical growth model, American Economic Review, 55, 1126-1150.

[11] Galor, O. and H.E. Ryder, 1989, Existence, uniqueness, and stability of equilibrium in an overlapping-generations model with productive capital, Journal of Economic Theory, 49, 360-375.

[12] Glomm, G. and B. Ravikumar, 1992, Public versus Private Investment in Human Capital: Endogenous Growth and Income Inequality, Journal of Political Economy, 100, 818-834. 
[13] Jones, L.E. and R.E. Manuelli, 1992, Finite lifetimes and growth, Journal of Economic Theory 58, 171-197.

[14] Lambrecht, S., Michel Ph. and E. Thibault, 2000, Intertemporal equilibrium with myopic altruism, WP GREQAM 00A24, University of Aix-Marseille II.

[15] Lambrecht, S., Michel Ph. and J.P. Vidal, 2005, Public pensions and growth, European Economic Review, Forthcoming.

[16] Mankiw, G., 2000, The savers-spenders theory of fiscal policy, American Economic Review, 90, 120-125.

[17] Michel, Ph. and P. Pestieau, 1998, Fiscal policy in a growth model with both altruistic and nonaltruistic agents. Southern Economic Journal, 64, 682-697.

[18] Michel, Ph. and P. Pestieau, 1999, Fiscal policy when individuals differ with regard to altruism and labor supply, Journal of Public Economic Theory, 1, 187-203.

[19] Michel, Ph., Thibault E. and J.P. Vidal, 2005, Intergenerational altruism and neoclassical growth models, Handbook of the Economics of Giving, Reciprocity and Altruism, North Holland, Forthcoming.

[20] O'Driscoll, G.P., 1977, The Ricardian nonequivalence theorem, Journal of Political Economy, 85, 207-210.

[21] Ricardo, D., 1820, Funding system, reprinted in: The works and correspondence of David Ricardo, published P. Sraffa, Cambridge University Press, 1951.

[22] Thibault, E., 2000, Existence of equilibrium in an OLG model with production and altruistic preferences, Economic Theory, 15, 709-715.

\section{Appendix A: Proof of Proposition 3}

Consider a steady state $k^{D}$ of the economy without altruism $(\gamma=0)$. Then in the economy with family altruism $(\gamma>0)$ we show that: (i) Inequality (19) is verified and $k^{D}$ is a steady state with zero bequest. (ii) Inequality (19) is not verified and there exists a steady state larger than $k^{D}$ (may be $+\infty$ ). 
(i) As seen, if $k^{D}$ verified (19), it is a steady state with zero bequest of the economy with family altruism.

(ii) If $k^{D}$ is not a steady-state of the economy with family altruism there are two possibilities. If it exists a Diamond equilibrium larger than $k^{D}$ which satisfies (19) this equilibrium is an equilibrium of model with family altruism. In the converse case, since the largest steady state $k_{\max }^{D}$ of the economy without altruism does not verified (19) we have:

$$
(1+n) u_{2}^{\prime}\left[(1+n) f^{\prime}\left(k_{\max }^{D}\right) k_{\max }^{D}\right]<\gamma u_{3}^{\prime}\left(w\left(k_{\max }^{D}\right)\right)
$$

This inequality implies that $\tilde{\omega}\left(k_{\max }^{D}\right)>w\left(k_{\max }^{D}\right)$ and that, if $k_{t}=k_{\max }^{D}$, then $k_{t+1}>k_{t}$. Indeed,

$$
\omega_{t}=\tilde{\omega}\left(k_{\max }^{D}\right)>(1+n) k_{\max }^{D}+g_{0}\left(k_{\max }^{D}\right) \geq(1+n) k_{\max }^{D}+\min \left\{g_{0}\left(k_{\max }^{D}\right), g_{1}\left(k_{\max }^{D}\right)\right\}
$$

and $\omega_{t}=(1+n) k_{t+1}+\min \left\{g_{0}\left(k_{t+1}\right), g_{1}\left(k_{t+1}\right)\right\}$ imply that $k_{t+1}>k_{\max }^{D}$.

Thus the equilibrium dynamics $\left\{k_{t}\right\}_{t=0}^{+\infty}$ starting at $k_{0}=k_{\max }^{D}$ is increasing. Either it goes to $+\infty$ or it converges to a steady state. When it converges to a finite limit, bequests at the steady state are necessarily positive because it is not a steady state of the economy without bequest. When it converges to $+\infty$, we may say that $+\infty$ is a "steady state" of the economy with family altruism, and, for large $t$, bequests are necessarily positive (zero bequests imply a decrease in $k$ for large $t$ ).

\section{Appendix B: Proof of Proposition 4}

We show that: (i) There can exists a multiplicity of steady state with positive bequests. (ii) There exists no more than one steady state with positive bequests and over-accumulation of capital. (iii) All the steady states with positive bequests are efficient if the condition (21) is verified.

(i) Assume that $U(c, d, \omega)=\ln c_{t}+\beta \ln d_{t+1}+\gamma u_{3}(\omega)$ and $f\left(k_{t}\right)=k_{t}^{\alpha}$ with $\alpha \leq 1 / 2$ such that $1+\beta<\alpha(1-\alpha) /(1-2 \alpha)$. For all positive $p$, we show in Appendix $\mathrm{C}$ that it exists a concave function $u_{3}$ such that the model with family altruism experiences at least $p$ equilibria with positive bequests.

(ii) According to (13), a steady state verifies if it exists:

$$
h(\omega, k) \equiv u_{1}^{\prime}[\omega-(1+n) k]-f^{\prime}(k) u_{2}^{\prime}[(1+n)(f(k)-\omega)]=0
$$

This condition defines a curve $C_{1}: \omega=\omega_{1}(k)$ such that:

$$
\omega_{1}^{\prime}(k)=-\frac{h_{k}^{\prime}(\omega, k)}{h_{\omega}^{\prime}(\omega, k)}=\frac{-(1+n) u_{1}^{\prime \prime}-f^{\prime \prime} u_{2}^{\prime}-(1+n) f^{\prime 2} u_{2}^{\prime \prime}}{-u_{1}^{\prime \prime}-(1+n) f^{\prime} u_{2}^{\prime \prime}}
$$


and if $f^{\prime}(k) \leq 1+n$, then $\omega_{1}^{\prime}(k)>f^{\prime}(k)$. But a steady state with positive bequests also verifies $\omega=\tilde{\omega}(k)$, i.e. $(k, \omega)$ belongs to the curve $C_{2}$ defined by $f(k)=\tilde{\omega}+\psi(\tilde{\omega})$; and we have (relation (11)) $\tilde{\omega}^{\prime}(k)<f^{\prime}(k)$. Since the two curves $C_{1}$ and $C_{2}$ verify $\tilde{\omega}^{\prime}(k)<\omega_{1}^{\prime}(k)$ for all $k \geq \hat{k}$, they cannot intersect more than once.

(iii) Moreover, the two curves $C_{1}$ and $C_{2}$ do not intersect (in over-accumulation of capital) when $\tilde{\omega}(\hat{k})<\omega_{1}(\hat{k})$. The value of $\hat{\omega}=\tilde{\omega}(\hat{k})$ is determined by $(1+n) u_{2}^{\prime}[(1+$ $n)(f(\hat{k})-\hat{\omega})]=\gamma u_{3}^{\prime}(\hat{\omega})$ and $\omega_{1}(\hat{k})>\hat{\omega}$ is equivalent to $(21)$.

\section{Appendix C: Steady states with Positive Bequests}

Assume that $U(c, d, \omega)=\ln c_{t}+\beta \ln d_{t+1}+\gamma u_{3}(\omega)$ and $f\left(k_{t}\right)=k_{t}^{\alpha}$ with $\alpha \leq 1 / 2$ such that $1+\beta<\alpha(1-\alpha) /(1-2 \alpha)$. For all positive $p$, we will show that it exists a concave function $u_{3}$ such that the model with family altruism experiences at least $p$ equilibria with positive bequests.

\section{Step 1: Characterization of equilibria with positive bequests.}

With our utility specification the function $\psi$ and $g_{1}$ of equation (9) and (16) are:

$$
\Psi(\omega)=\frac{\beta}{\gamma u_{3}^{\prime}(\omega)} \quad \text { and } \quad g_{1}(k)=\frac{(1+n) k^{1-\alpha}}{\alpha \gamma u_{3}^{\prime}(\omega)}
$$

Then, since $f(k)=k^{\alpha}=\omega+\Psi(\omega)$ we have $k=\left(\omega+\frac{\beta}{\gamma u_{3}^{\prime}(\omega)}\right)^{1 / \alpha}$.

Therefore, the $\omega$ which are equilibria with positive bequests must satisfy :

$$
\begin{gathered}
\omega=(1+n)\left(\omega+\frac{\beta}{\gamma u_{3}^{\prime}(\omega)}\right)^{1 / \alpha}+g_{1}\left(\left(\omega+\frac{\beta}{\gamma u_{3}^{\prime}(\omega)}\right)^{1 / \alpha}\right) \\
\omega>(1-\alpha)\left(\omega+\frac{\beta}{\gamma u_{3}^{\prime}(\omega)}\right)
\end{gathered}
$$

Hence, any $\omega$ which satisfies the two following conditions is an equilibrium with positive bequests:

$$
\begin{aligned}
\omega^{\frac{1-\alpha}{\alpha}}\left(1+\frac{\beta}{\gamma \omega u_{3}^{\prime}(\omega)}\right)^{\frac{1}{\alpha}} & \left(1+\frac{1}{\alpha \beta+\alpha \gamma \omega u_{3}^{\prime}(\omega)}\right)-\frac{1}{1+n}=0 \\
\gamma & >\frac{(1-\alpha) \beta}{\alpha \omega u_{3}^{\prime}(\omega)}
\end{aligned}
$$

Step 2: Construction and variation of pairs $(\bar{\omega}, \bar{\sigma})$.

For all positive $\mu$, we can define $\bar{\omega}$ and $\bar{\sigma}$ such that:

$$
\bar{\omega}=(1+n)^{\frac{\alpha}{\alpha-1}}\left(1+\frac{\alpha}{(1-\alpha) \mu}\right)^{\frac{1}{\alpha-1}}\left(1+\frac{1}{\beta(\alpha+(1-\alpha) \mu)}\right)^{\frac{\alpha}{\alpha-1}}
$$




$$
\bar{\sigma}=\frac{\mu(1-\alpha) \beta}{\alpha \gamma \bar{\omega}}=\frac{\mu(1-\alpha) \beta}{\alpha \gamma(1+n)^{\frac{\alpha}{\alpha-1}}}\left(1+\frac{\alpha}{\mu(1-\alpha)}\right)^{\frac{1}{1-\alpha}}\left(1+\frac{1}{\beta(\alpha+(1-\alpha) \mu)}\right)^{\frac{\alpha}{1-\alpha}}
$$

It is obvious to show that $\bar{\omega}$ increases with respect to $\mu$.

Since $\bar{\sigma}=f(\mu)=A * B(\mu)^{\frac{1}{1-\alpha}} * C(\mu)^{\frac{\alpha}{1-\alpha}}$ where $A=\left[(1+n)^{\frac{\alpha}{1-\alpha}} \beta\right] / \gamma, B(\mu)=$ $[\mu(1-\alpha)) / \alpha]^{1-\alpha}+[\mu(1-\alpha) / \alpha]^{-\alpha}$, and $C(\mu)=1+1 /[\beta(\alpha+(1-\alpha) \mu)]$ we have:

$$
f^{\prime}(\mu)=\frac{A}{1-\alpha} B^{\prime}(\mu) B(\mu)^{\frac{\alpha}{1-\alpha}} C(\mu)^{\frac{\alpha}{1-\alpha}}+\frac{\alpha A}{1-\alpha} B(\mu)^{\frac{1}{1-\alpha}} C^{\prime}(\mu) C(\mu)^{\frac{2 \alpha-1}{1-\alpha}}
$$

Hence $f^{\prime}(1)$ has the sign of $B^{\prime}(1)+\alpha B(1) C^{\prime}(1) / C(1)$.

Since $B(1)=\alpha^{\alpha-1} /(1-\alpha)^{\alpha}, B^{\prime}(1)=\alpha^{\alpha-1}(1-2 \alpha) /(1-\alpha)^{\alpha}, C(1)=(1+\beta) / \beta$ and $C^{\prime}(1)=(\alpha-1) / \beta, f^{\prime}(1)$ has the sign of $(1-2 \alpha)(1+\beta)+\alpha(\alpha-1)$. Hence $f^{\prime}(1)$ is negative. Thus it exists $\kappa>0$ such that $\forall \mu \in] 1-\kappa, 1+\kappa\left[\quad f^{\prime}(\mu)<0\right.$.

\section{Step 3: Existence of $u_{3}$ to obtain $p$ equilibria with positive bequests.}

Let $p$ be a positive integer. According to step 2 we can construct an increasing sequence of real numbers $\mu_{1}, \mu_{2}, \ldots, \mu_{p}$ such that:

$$
\forall i \in 1, \ldots, p \quad 1<\mu_{i}<1+\kappa \quad \text { and } \quad f^{\prime}\left(\mu_{i}\right)<0
$$

For each $\mu_{i}$ we construct the pair $\left(\bar{\omega}_{i}, \bar{\sigma}_{i}\right)$ studied in step 2 .

Since $\bar{\omega}_{1}, \bar{\omega}_{2}, \ldots, \bar{\omega}_{p}$ are distinct, it exists a differentiable decreasing function $u_{3}^{\prime}: \mathbb{R}^{+} \rightarrow \mathbb{R}^{+}$such that

$$
\forall i \in 1, \ldots, p \quad v^{\prime}\left(\bar{\omega}_{i}\right)=\bar{\sigma}_{i}
$$

The function $u_{3}^{\prime}$ can be decreasing because $\partial \bar{\omega}_{i} / \partial \mu_{i}>0$ and $f^{\prime}\left(\mu_{i}\right)<0$ implies $\partial \bar{\sigma}_{i} / \partial \mu_{i}<0$. Since $u_{3}^{\prime}(\omega)$ is integrable (because continuous) we can construct a differentiable function $u_{3}(\omega)$ such that its derivative is the function $u_{3}^{\prime}(\omega)$. And, since $u_{3}^{\prime}$ is a decreasing function, $u_{3}$ is a concave function.

By construction, for all $i$ we have $\bar{\omega}_{i} u_{3}^{\prime}\left(\bar{\omega}_{i}\right)=\left[\mu_{i}(1-\alpha) \beta\right] /(\alpha \gamma)$.

Then, since $\mu_{i}>1, \bar{\omega}_{i}$ satisfies $(26)$.

Moreover, substituting $\bar{\omega}_{i} u_{3}^{\prime}\left(\bar{\omega}_{i}\right)$ by $\left[\mu_{i}(1-\alpha) \beta\right] /(\alpha \gamma)$ in $(25)$, we can easily check that $\bar{\omega}_{i}$ also satisfies (25).

Therefore, we have constructed a concave function $u_{3}$ such that the $p \bar{\omega}_{i}$ 's verify (25) and (26). Hence, according to step 1, our model has at least $p$ equilibria with positive bequests. 